\title{
Regional cerebral blood flow and cognitive function in patients with obsessive- compulsive disorder
}

\author{
Fluxo sanguíneo regional cerebral e função cognitiva em pacientes com \\ transtorno obsessivo compulsivo
}

Huirong Guo ${ }^{1}$, Ning Zhao', Zheng Li', Binhua Zhu' ${ }^{1}$, He Cui', Youhui Li ${ }^{1 *}$

\begin{abstract}
Objective: To explore the relationship between regional cerebral blood flow (CBF) and cognitive function in obsessive-compulsive disorder (OCD). Method: Single-photon emission computed tomography (SPECT) was performed for 139 OCD patients and 139 controls, and the radioactivity rate (RAR) was calculated. Cognitive function was assessed by the Wisconsin Card Sorting Test (WCST). Results: The RARs of the prefrontal, anterior temporal, and right occipital lobes were higher in patients than controls. For the WCST, correct and classification numbers were significantly lower, and errors and persistent errors were significantly higher in OCD patients. Right prefrontal lobe RAR was negatively correlated with correct numbers, right anterior temporal lobe RAR was positively correlated with errors, and the RARs of the right prefrontal lobe and left thalamus were positively correlated with persistent errors. Conclusion: OCD patients showed higher CBF in the prefrontal and anterior temporal lobes, suggesting that these areas may be related with cognitive impairment.
\end{abstract}

Keywords: obsessive-compulsive disorder, regional cerebral blood flow, cognitive function.

RESUMO

Objetivo: Estudar a relação entre a perfusão sanguínea regional cerebral e as funções cognitivas em pacientes com transtorno obsessivo compulsivo (TOC). Método: Foram estudados 139 pacientes com TOC e 139 controles. As imagens do fluxo sanguíneo cerebral foram feitas por single photon emission computed tomography e o radioactivity rate (RAR) foi calculado usando como referência a radioatividade do córtex cerebelar. As funções cognitivas foram avaliadas através do Wisconsin Card Sorting Test (WCST). Resultados: O RAR do lobo pré-frontal, do lobo temporal anterior e do lobo occipital direito foram mais elevados nos pacientes do que nos controles (P<0.05). Quanto ao WCST, os escores de números corretos $(P<0.01)$ e de classificação $(P<0.05)$ foram menores no grupo TOC do que nos controles; entretanto, os escores de erros e de erros persistentes nos controles foram mais elevados do que nos pacientes $(P<0.01)$. O RAR do lobo pré-frontal direito estava relacionado de modo negativo com os números corretos; o RAR do lobo temporal anterior apresentava correlação positiva com os erros; o RAR do lobo pré-frontal direito e do tálamo esquerdo apresentavam correlação positiva com erros persistentes. Conclusão: Pacientes com TOC apresentaram perfusão sanguínea cerebral mais intensa no lobo pré-frontal e no lobo temporal anterior. O lobo pré-frontal direito, o lobo temporal e o tálamo esquerdo podem estar relacionados com alterações cognitivas.

Palavras-chave: transtorno obsessivo-compulsivo, fluxo sanguíneo regional cerebral, função cognitiva.

Obsessive-compulsive disorder (OCD) is an intractable psychiatric condition. OCD morbidity is $2-3 \%$, which severely affects patients' quality of life ${ }^{1}$. In order to investigate the biological basis underlying changes in cerebral function in patients with OCD, we assessed cerebral blood flow (CBF) with single-photon emission computed tomography (SPECT) and compared the results with cognitive function as assessed by the Wisconsin Card Sorting Test (WCST).

\footnotetext{
'Department of Psychiatry, The First Affiliated Hospital of Zhengzhou University, Zhengzhou;

${ }^{2}$ Department of Neurology, Henan Provincial People's Hospital.

Correspondence:Youhui Li; Department of Psychiatry; The First Affiliated Hospital of Zhengzhou University; Zhengzhou 450052 - China; E-mail: liyouhuiyoga@163.com

Conflict of interest: There is no conflict of interest to declare.

Support: The present research was funded by The Science and Technology Research Funded Projects of Henan Provincial Health Bureau (200703056).

Received 22 April 2013; Received in final form 17 July 2013; Accepted 24 July 2013.
} 


\section{METHODS}

\section{Subjects}

OCD subjects were chosen from patients who were treated at the Psychiatric Department of the First Affiliated Hospital of Zhengzhou University. All of the subjects were untreated and in their first episode, with Yale-Brown Obsessive Compulsive Scale (Y-BOCS) $\geq 16$ and symptoms in agreement with the diagnostic criteria of the $10^{\text {th }}$ revision of the International Statistical Classification of Diseases and Related Health Problems (ICD-10). Patients with other mental disorders, somatic disease, pregnancy, or lactation and patients who once had taken medicine for cerebrovascular diseases or psychological disorders, hormone drugs, or contraceptive pills in the preceding month were excluded. A total of 139 patients were included, ( 86 male and 53 female), with ages ranging from 17-49 (26.4 \pm 7.8$)$. The score range of the subjects tested with Yale-Brown Obsessional Scale was 16-39 (29.32 \pm 8.75$)$. The scores of the subjects examined with Hamilton Depression Scale (HAMD) ranged from 9-19 (15.33 \pm 3.11$)$. The scores of Hamilton Anxiety Scale (HAMA) were between 2 and 13 (7.97 \pm 5.02$)$. A total of 139 control subjects were selected from among First Affiliated Hospital of Zhengzhou University employees and Zhengzhou University undergraduate students, including 86 males and 53 females ranging from 19-49 years old (27.8 \pm 7.0$)$. There were no statistically significant differences between the two groups with regard to gender or age $(\mathrm{P}>0.05)$. All the subjects were informed about the research and agreed to participate.

\section{SPECT imaging}

The subjects took oral potassium chlorate (400 mg) to block ${ }^{99} \mathrm{mTcO} 4$ intake by the choroid plexus. Thirty minutes later, the subjects were injected with $9.25 \times 10^{9} \mathrm{~Bq}$ of ${ }^{99} \mathrm{mTc}^{-}$ ethycysteine dimer (ECD) via the median cubital vein. After 1 hour, the subjects were scanned with a dual head SPECT (GE Millennium Hawkeye VG) equipped with parallel hole, low-energy, high-resolution collimators. Matrices $(64 \times 64)$ were captured, stepping 6 degree, and a total of 60 frames were collected with $35 \mathrm{~s}$ per frame. A Butterworth filter was used for rescanning, and the cross-section was paralleled to the orbitomeatal line. All of the subjects were examined between 10:00 and 11:00 A.M.. The ratio between the mean radioactivity rate (RAR) in each brain region and that in the cerebellum was calculated by overlaying two or three regions of interest (ROIs) into a dataset and taking the mean RAR of the bilateral cerebella as a reference value.

\section{Cognitive function assessment}

We employed the revised version of the WCST comprised of 4 stimulus cards and 48 response cards ${ }^{2}$. The cards were printed with designs with different numbers (from 1 to 4), colors (red, yellow, green, and blue) and shapes (rectangular, round, five-star, and triangular) that can be classified by color, shape, or number. If the subjects correctly classified the cards by color six consecutive times, they converted to the following classification (e.g., shape), and then did the next classification (e.g., number). After the three kinds of classification, the classifications were repeated once more. If the subjects accomplished classification correctly six times in total or used up all 48 cards without successful completion, the examination was ended. The observation indices included the total numbers of correct, error, preservative errors, non-maintained errors, and finished classification.

\section{Statistics}

All data are expressed as mean \pm standard deviation (SD) and were assessed with SPSS13.0 statistical software (SPSS Inc., Chicago, IL, USA). Statistical differences were calculated for brain RAR values and WCST results using the Student's $t$ test, followed by a Pearson correlation analysis to determine the relationship between the two groups. $\mathrm{P}<0.05$ was considered statistically significant.

\section{RESULTS}

\section{SPECT results}

The RAR of the bilateral prefrontal lobes $(\mathrm{P}<0.01)$, anterior temporal lobe $(\mathrm{P}<0.01)$, and right occipital lobe $(\mathrm{P}<0.05)$ were significantly higher in patients with OCD than in control subjects (Table 1).

\section{WCST results}

As shown in Table 2, for the WCST, scores of correct numbers $(\mathrm{P}<0.01)$ and classification numbers $(\mathrm{P}<0.05)$ in OCD patients were lower than those of the control group, and scores of errors and persistent errors were higher in patients than in controls $(\mathrm{P}<0.01)$.

\section{Relationship between RAR and cognitive function in OCD patients}

As shown in Table 3, the RAR value of the right prefrontal lobe was negatively correlated with the correct number score $(\mathrm{r}=-0.783, \mathrm{P}=0.014)$, the right anterior temporal lobe RAR was positively correlated with the error score $(\mathrm{r}=0.384, \mathrm{P}=0.047)$, and the RARs of the right prefrontal lobe and left thalamus were positively correlated with the persistent error score ( $r=0.511, \mathrm{P}=0.041 ; \mathrm{r}=0.610, \mathrm{P}=0.049)$.

\section{DISCUSSION}

Functional brain imaging of patients with OCD has become a research topic of interest in recent years. Trivedi ${ }^{3}$ found that blood perfusion was abnormal in the neural 
Table 1. RARs by brain region.

\begin{tabular}{|c|c|c|c|c|}
\hline Encephalic region & OCD & Control & $\mathrm{t}$ & $\mathrm{P}$ \\
\hline Left prefrontal lobe & $94.4 \pm 6.1$ & $88.3 \pm 7.1^{*}$ & 6.78 & $0.001^{* *}$ \\
\hline Right prefrontal lobe & $99.8 \pm 6.4$ & $86.9 \pm 7.9^{*}$ & 11.93 & $<0.001^{\star *}$ \\
\hline Left aboral frontal lobe & $93.7 \pm 6.3$ & $98.6 \pm 8.0$ & -1.14 & 0.560 \\
\hline Right aboral frontal lobe & $96.3 \pm 9.4$ & $92.9 \pm 9.2$ & 1.62 & 0.101 \\
\hline Left anterior temporal lobe & $91.6 \pm 6.1$ & $84.0 \pm 7.2^{*}$ & 7.15 & $0.002^{* *}$ \\
\hline Right anterior temporal lobe & $92.8 \pm 6.6$ & $84.4 \pm 7.3^{*}$ & 9.40 & $<0.001^{* *}$ \\
\hline Left aboral temporal lobe & $94.9 \pm 7.5$ & $99.5 \pm 9.6$ & 4.64 & 0.055 \\
\hline Right aboral temporal lobe & $92.9 \pm 6.6$ & $94.7 \pm 8.1$ & -2.00 & 0.315 \\
\hline Left cingulate gyrus & $92.8 \pm 5.4$ & $96.2 \pm 7.9$ & -2.22 & 0.188 \\
\hline Right cingulate gyrus & $93.1 \pm 6.1$ & $95.4 \pm 8.7$ & -0.85 & 0.673 \\
\hline Left parietal lobe & $96.1 \pm 7.5$ & $93.8 \pm 10.9$ & 1.95 & 0.650 \\
\hline Right parietal lobe & $96.0 \pm 6.6$ & $92.4 \pm 9.4$ & 0.48 & 0.060 \\
\hline Left occipital lobe & $101.9 \pm 8.1$ & $97.5 \pm 11.2$ & 0.48 & 0.059 \\
\hline Right occipital lobe & $102.3 \pm 7.7$ & $96.4 \pm 10.2$ & 4.89 & $0.043^{*}$ \\
\hline Left basal ganglia & $85.9 \pm 6.9$ & $88.6 \pm 4.0$ & -3.64 & 0.078 \\
\hline Right basal ganglia & $87.5 \pm 6.1$ & $89.4 \pm 8.9$ & -2.63 & 0.201 \\
\hline Left thalamus & $80.7 \pm 8.8$ & $82.5 \pm 9.1$ & -2.38 & 0.337 \\
\hline Right thalamus & $78.6 \pm 8.5$ & $83.4 \pm 10.0$ & -4.01 & 0.062 \\
\hline
\end{tabular}

Values are mean $\pm S D{ }^{*} P<0.05{ }^{*} P<0.01$. OCD: obsessive-compulsive disorder; RAR: radioactivity rate.

Table 2. WCST scores.

\begin{tabular}{lcccc}
\hline Item & OCD & Control & $\mathrm{t}$ & $\mathrm{P}$ \\
\hline Scores of corrects & $33.24 \pm 5.39$ & $38.15 \pm 4.64$ & -3.657 & $0.006^{* *}$ \\
Scores of errors & $13.21 \pm 6.89$ & $7.53 \pm 5.97$ & 5.881 & $0.000^{* *}$ \\
Persistent errors & $6.79 \pm 4.89$ & $2.06 \pm 1.29$ & 4.873 & $0.001^{* *}$ \\
Non-maintained & $6.49 \pm 2.74$ & $5.59 \pm 4.41$ & 1.713 & 0.139 \\
errors & & & & \\
Complete & $4.42 \pm 1.62$ & $5.72 \pm 0.94$ & -2.595 & $0.012^{*}$ \\
Classification & & & &
\end{tabular}

Values are mean $\pm S D{ }^{*} P<0.05{ }^{* *} P<0.01$. WCST: Wisconsin Card Sorting Test; OCD: obsessive-compulsive disorder.

circuit of the prefrontal lobe-cingulate gyrus-basal ganglia region, with increased blood perfusion in this region. However, other studies ${ }^{4}$ indicated that functional changes in patients with OCD only involved individual brain areas. Alptekin and colleagues $^{4}$ performed SPECT and described significantly increased perfusion of the bilateral prefrontal lobe cortex in patients with OCD. Adler ${ }^{5}$ found that the front of the bilateral temporal lobe cortex in untreated patients with OCD was obviously activated after their symptoms were stimulated during functional brain imaging. The reasons for these differences could be due to patients with obvious anxiety and depression or taking medication. In this study, we performed brain imaging of patients who were newly diagnosed with OCD. The results indicated that patients with OCD had higher perfusion of the cerebral cortex compared with normal controls, which supported the previous description of increased CBF; however, the areas showing increases were mainly located in the prefrontal and anterior temporal lobes, indicating that abnormal function in the frontal and temporal lobes may contribute to the onset of OCD, which does not support the previous view of neural circuit dysfunction. The frontal lobe is involved in abstract thinking, and the prefrontal lobe is associated with goal-directed action, working memory, and executive function. The temporal lobe is responsible for memory, perception, and emotion. Clinically, patients with OCD are characterized by thinking-transfer dysfunction, excessive focus on details, and morbid hypermnesia about unnecessary fears, which are relevant to dysfunction of the frontal and temporal lobes.

Many patients with mental disorders have cognitive functional dysfunction. Previous studies demonstrated that patients with OCD exhibit extensive cognitive functional dysfunction including the domains of attention, memory, abstract thinking, and spatial memory ${ }^{6,7}$. Research has shown that OCD patients with depression have obviously decreased executive function ${ }^{8}$. In this study, cognitive functional testing revealed that the performance of patients with OCD for the total number of correct responses, total error number, preservative error number, and number of categories was much worse than that of the control group, which demonstrates that attention and executive function were impaired in patients with OCD. The reason may be that patients with OCD could not concentrate on a task, and when they made mistakes, patients with OCD tended to pay excessive attention to the wrong rules, which had an unfavorable effect on making judgments of correct rules. Thus, they needed to spend more time changing their ways of solving problems and checking whether an answer was correct in the next round. Therefore, our results are in accordance with those reported by Savage and colleagues? 
Table 3. Pearson correlation analysis between RAR values and WCST performance.

\begin{tabular}{|c|c|c|c|c|c|c|c|c|c|c|}
\hline \multirow{2}{*}{ Encephalic region } & \multicolumn{2}{|c|}{ Scores of corrects } & \multicolumn{2}{|c|}{ Scores of errors } & \multicolumn{2}{|c|}{ Persistent errors } & \multicolumn{2}{|c|}{ Non-maintained errors } & \multicolumn{2}{|c|}{ Classification } \\
\hline & $r$ & $\mathrm{P}$ & $r$ & $\mathrm{P}$ & $r$ & $\mathrm{P}$ & $r$ & $\mathrm{P}$ & $r$ & $\mathrm{P}$ \\
\hline Left prefrontal lobe & 0.057 & 0.751 & -0.095 & 0.601 & 0.014 & 0.937 & -0.322 & 0.067 & 0.111 & 0.540 \\
\hline Right prefrontal lobe & -0.783 & $0.014^{*}$ & 0.042 & 0.818 & 0.511 & $0.041^{*}$ & -0.217 & 0.225 & 0.110 & 0.541 \\
\hline Left aboral frontal lobe & 0.228 & 0.203 & -0.202 & 0.259 & -0.154 & 0.392 & -0.258 & 0.147 & 0.175 & 0.331 \\
\hline Right aboral frontal lobe & -0.094 & 0.603 & 0.121 & 0.502 & 0.149 & 0.407 & 0.009 & 0.962 & -0.111 & 0.537 \\
\hline Left anterior temporal lobe & -0.031 & 0.865 & -0.058 & 0.750 & 0.045 & 0.805 & -0.231 & 0.196 & -0.013 & 0.943 \\
\hline Right anterior temporal lobe & 0.245 & 0.170 & 0.384 & $0.047^{*}$ & -0.170 & 0.344 & -0.246 & 0.189 & 0.279 & 0.116 \\
\hline Left aboral temporal lobe & 0.003 & 0.985 & -0.016 & 0.932 & 0.100 & 0.581 & -0.224 & 0.211 & 0.022 & 0.904 \\
\hline Right aboral temporal lobe & 0.133 & 0.459 & -0.217 & 0.224 & -0.095 & 0.598 & -0.277 & 0.193 & 0.263 & 0.139 \\
\hline Left cingulate gyrus & 0.260 & 0.143 & -0.338 & 0.054 & -0.238 & 0.180 & -0.406 & 0.119 & 0.283 & 0.110 \\
\hline Right cingulate gyrus & 0.307 & 0.126 & -0.296 & 0.073 & -0.082 & 0.373 & -0.455 & 0.106 & 0.178 & 0.243 \\
\hline Left parietal lobe & 0.135 & 0.453 & -0.141 & 0.435 & -0.030 & 0.868 & -0.327 & 0.063 & 0.123 & 0.494 \\
\hline Right parietal lobe & 0.142 & 0.429 & -0.139 & 0.441 & -0.071 & 0.695 & -0.250 & 0.161 & 0.058 & 0.749 \\
\hline Left occipital lobe & -0.111 & 0.538 & 0.084 & 0.641 & 0.082 & 0.648 & 0.076 & 0.673 & -0.190 & 0.289 \\
\hline Right occipital lobe & -0.340 & 0.053 & 0.323 & 0.067 & 0.306 & 0.052 & 0.184 & 0.305 & -0.143 & 0.251 \\
\hline Left basal ganglia & 0.206 & 0.250 & -0.226 & 0.206 & -0.203 & 0.256 & -0.199 & 0.267 & 0.229 & 0.200 \\
\hline Right basal ganglia & 0.057 & 0.752 & -0.07 & 0.697 & -0.015 & 0.935 & -0.156 & 0.387 & 0.025 & 0.889 \\
\hline Left thalamus & -0.262 & 0.140 & 0.249 & 0.163 & 0.610 & $0.049^{*}$ & 0.078 & 0.668 & -0.254 & 0.154 \\
\hline Right thalamus & -0.304 & 0.085 & 0.231 & 0.196 & 0.266 & 0.134 & 0.117 & 0.518 & -0.299 & 0.091 \\
\hline
\end{tabular}

${ }^{*} \mathrm{P}<0.05$; RAR: radioactivity rate; WCST: Wisconsin Card Sorting Test.

There have been some reports about the relationship between brain function abnormalities and cognitive deficits. In 1997, Lucey et al. ${ }^{10}$ assessed controls and subjects with OCD (19 in each group) with the WCST and SPECT and discovered a positive correlation between obsessive thinking and error number and a negative correlation between the number of categories achieved and perfusion of the inferior prefrontal gyrus and left caudate nucleus. Lacerda et al. ${ }^{11}$ performed a similar study and identified a positive correlation between perfusion of the frontal lobe and anterior cingulate gyrus and non-persistent errors. In addition, their results revealed that perfusion of the right thalamus was negatively correlated with the number of preservative errors, which was positively correlated with symptom severity. In the present study, we analyzed the relationship between WCST results and SPECT imaging in subjects with OCD. The results demonstrated that perfusion of the right prefrontal lobe was negatively correlated with the categories-achieved number, perfusion of the right anterior temporal lobe was positively correlated to error number, and perfusion of the right prefrontal lobe and left thalamus were positively correlated with preservative errors. These findings suggest that dysfunction of the frontal and temporal lobes and thalamus may play a key role in cognitive impairment in patients with OCD. Considering that there are various clinical phenotypes of $\mathrm{OCD}$, the inclusion of more subjects would increase the significance of our results.

In conclusion, OCD patients exhibited higher CBF, mainly in the prefrontal and anterior temporal lobes and the left thalamus, indicating that these regions may play important roles in cognitive impairment in OCD.

\section{Acknowledgements}

The authors would like to thank Prof. Zeping Xiao at Shanghai Mental Health Center and Prof. Wei Gu at The Second Xiangya Hospital of Central South University for their valuable help and assisting in revising the manuscript.

\section{References}

1. Chamberlain SR, BlackwellAD, Fineberg NA, etal.The neuropsychology of OCD: the importance of failures in cognitive and behavioural inhibition as candidate endophenotypic makers. Neurosci Biobehav Rev 2005;29:399-419.

2. Zhang $L X$, Yang $Y C$, et al. A study of cognitive function in OCD patients. Chinese J Psychiatry 2005;38:23-26.

3. Trivedi $\mathbf{M H}$. Functional neuroanatomy of obsessive-compulsive disorder.J Clin Psychiatry 1996;57:26-28.
4. Alptekin K, Degirmenci B, Kivircik B, et al. Tc-99m HMPAO brain perfusion SPECT in drug-free obsessivecompulsive patients without depression. Psychiatry Res 2001;107:51-56

5. Adler CM, McDonough-Ryan P, Sax KW, Holland SK, Arndt S, StrakowskiSM. fMRI of neuronal activation with symptom provocation in unmedicated patients with obsessive-compulsive disorder. J Psychiatr Res 2000;34:317-324. 
6.

Clayton IC, Richard JC, Edwards CJ. Selective attention in obsessivecompulsive disorder. J Abnorm Psychol 1999;108:171-175.

7. Okasha A, Rafaat M, Mahallawy $N$, et al. Cognitive dysfunction in obsessive-compulsive disorder. Acta Psychiatr Scand 2000;101:281-285.

8. Aycicegi A, Dinn WM, Harris CL, Erkmen H. Neuropsychological function in obsessive compulsive disorder: effects of comorbid conditions on task performance. Eur Psychiatry 2003;18:241-248.
9. Savage CR, Baer L, Keuthen NJ, Brown HD, Rauch SL, Jenike MA. Organizational strategies mediate nonverbal memory impairment in obsessive-compulsive disorder. Biol Psychiatry 1999;5:905-916.

10. Lucey JV, Burness CE, Costa DC, et al. WCST errors and cerebral blood flow in OCD. Br.J Med Psychol 1997;70:403-411.

11. Lacerda AL, Dalgalarrondo P, Caetano D, Haas GL, Camargo EE, Keshavan MS. Neuropsychological performance and regional cerebral blood flow in OCD. Prog Neuropsycholopharmacol Biol Psychiatry 2003;27:657-665. 